\title{
Consultant perception of general internal medicine: a survey of consultant physicians
}

\author{
Authors: Abigail Moore, ${ }^{A}$ Nina Newbery ${ }^{B}$ and Andrew F Goddard ${ }^{C}$
}

\begin{abstract}
The Future Hospital Commission has highlighted the need for increased general medical skills in the medical workforce in order to meet the increasing demands on the NHS in terms of patients with increasing age, frailty and complex comorbidities. However there continues to be a lack of clarity around the concept of generalism and general internal medicine (GIM), with differing views on the physician's role in GIM. This survey sought to explore further the roles in which current physicians perceive they are practising GIM as well as views on training in GIM. The survey highlights three key points: (i) that consultant perception and practice of GIM continues to vary dependent on physician specialty; (ii) that the practice of GIM is not limited to the front door but includes the management of patients under the care of a specialty team with general medical needs, be that in an inpatient, outpatient or acute care setting; and (iii) that training in GIM needs to reflect this variation in roles and practice.
\end{abstract}

KEYWORDS: General internal medicine, GIM, consultant physician

\section{Introduction}

Since its inception in 1948, the burden on the NHS has increased significantly. Life expectancy has increased, patients are more complex and hospital bed numbers have reduced. It is predicted that the number of centenarians in the UK will rise from 14,000 in 2013 to 111,000 by $2037 .{ }^{1}$ Reports suggest that 15 million people in the UK have at least one long-term condition accounting for $77 \%$ of all hospital admissions. ${ }^{2}$ The numbers of hospital admissions in those patients over 75 years has risen more than that for all age groups combined from $38 \%$ in $2003 / 4$ to $57 \%$ in $2013 / 4 .{ }^{3}$ In this context, it is unsurprising that physicians are feeling the pressure in continuing to provide the high-quality patient care that they aspire to. ${ }^{4}$

Many individuals and bodies have called for increased 'generalism' within our medical workforce to deal with these problems. ${ }^{5,6}$ The Shape of Training report suggested changes in the structure of postgraduate medical training in order to

Authors: ${ }^{\text {A }}$ linical fellow, Royal College of Physicians, London, UK; ${ }^{B}$ manager, Medical Workforce Unit, Royal College of Physicians, London, UK; C registrar, Royal College of Physicians, London, UK re-enforce the need for more doctors who can provide general care in broad specialties across a range of different settings. ${ }^{7}$ However, in a response to the publication of this report, the BMA highlighted a lack of clarity around the concept of 'generalism' in medicine. ${ }^{8}$

However, data from the Royal College of Physicians' (RCP's)

Higher Specialty Trainee Census suggest that providing a workforce with the general internal medical skills to treat patients may prove challenging. The medical registrar post is often seen as overworked and undervalued with many trainees avoiding specialties in which they will need to take on the role. ${ }^{9,10}$ Satisfaction in general internal medicine (GIM) training is falling with the number of higher specialty trainees being very satisfied or satisfied falling from $50.1 \%$ in $2011 / 12$ to $40.1 \%$ in $2013 / 14$. Within the consultant workforce those specialties that have little contribution to acute medicine or who are not currently dual accrediting with GIM frequently are seen as those offering the most enjoyment and greatest job satisfaction. ${ }^{11}$

In order to explore these issues further we surveyed consultant members and fellows of the RCP. In particular we focused on the current perception of GIM by consultant physicians, the roles in which physicians are practising that they would define as GIM, and consultant physician views of GIM training.

\section{Methods}

An electronic survey formed using Vovici software was emailed to all consultant members and fellows of the Royal College of Physicians London. The survey was sent out on 23 March 2015 with reminders at 2 and 3 weeks on 7 April 2015 and 15 April 2015. A copy of the survey as sent to all participants can be viewed at www.rcpworkforce.com/se.ashx?s=253122AC27387908. The survey was closed after 4 weeks. Demographic data were collected on name and General Medical Council (GMC) number. Using participants' GMC numbers, data were retrieved from the RCP Medical Workforce Unit Database regarding age and primary specialty of all respondents.

The survey questions covered two main areas:

$>$ current practice in GIM

> views on training in GIM (for those who were involved in the educational or clinical supervision of higher specialty trainees).

Questions on current practice explored the roles and settings in which physicians perceived they were practising GIM currently. 
Those questions on training focused on the respondents' confidence in providing knowledge- and procedure-based training to trainees in GIM, as well as exploring views on the training time that should be spent on different aspects of internal medicine.

\section{Results}

\section{Response rates}

The survey was sent to 10,882 consultant members and fellows of the Royal College of Physicians of London. The survey was completed by 2,478 consultant physicians; a response rate of $23 \%$. Of those completing the survey questions, $66 \%$ were male and $34 \%$ were female, matching the gender distribution across the consultant workforce at present. Respondents were distributed over the range of age groups as follows: $<34$ years (1\%); 35-39 years $13 \%) ; 40-44$ years $(20 \%) ; 45-49$ years $(23 \%) ; 50-54$ years $(18 \%) ; 55-59$ years $(17 \%) ; 60-65$ years $(8 \%) ;>65$ years $(2 \%)$. Distribution of responses by specialty can be seen in Table 1.

Does your specialty provide a specialty-specific formal on-call service for the hospital in which you work?

All respondents were asked about the availability of a specialtyspecific on-call rota for their specialty within the hospital in which they work. Overall $64 \%$ of respondents answered that their specialty did provide a specialty-specific rota, compared to $36 \%$ who did not. The availability of a specialty rota varied depending on the specialty within which respondents worked (see Fig 1), with nearly all haematologists (97\%) providing a

Table 1. Distribution of survey respondents by specialty.

\begin{tabular}{|c|c|c|}
\hline Specialty & Respondents, $\mathrm{n}$ & $\begin{array}{l}\text { UK consultants in this specialty } \\
\text { who responded to the survey, \% }\end{array}$ \\
\hline Acute internal medicine & 146 & 30 \\
\hline Allergy & 7 & 24 \\
\hline Audiovestibular medicine & 15 & 32 \\
\hline Cardiology & 183 & 16 \\
\hline Clinical genetics & 33 & 16 \\
\hline Clinical neurophysiology & 23 & 19 \\
\hline Clinical pharmacology and therapeutics & 18 & 25 \\
\hline Dermatology & 111 & 15 \\
\hline Endocrinology and diabetes mellitus & 195 & 24 \\
\hline Gastroenterology & 243 & 21 \\
\hline General internal medicine & 34 & 20 \\
\hline Genitourinary medicine and HIV/AIDS & 71 & 17 \\
\hline Geriatric medicine & 329 & 25 \\
\hline Haematology & 90 & 10 \\
\hline Hepatology & 25 & 21 \\
\hline Immunology & 12 & 18 \\
\hline Infectious diseases and tropical medicine & 35 & 19 \\
\hline Intensive care medicine & 17 & $\mathrm{~N} / \mathrm{A}$ \\
\hline Medical oncology & 62 & 15 \\
\hline Medical ophthalmology & 2 & 15 \\
\hline Neurology & 116 & 15 \\
\hline Nuclear medicine & 10 & 13 \\
\hline Paediatric cardiology & 5 & 5 \\
\hline Palliative medicine & 103 & 21 \\
\hline Rehabilitation medicine & 29 & 18 \\
\hline Renal medicine & 117 & 21 \\
\hline Respiratory medicine & 241 & 22 \\
\hline Rheumatology & 163 & 22 \\
\hline Sport and exercise medicine & 1 & 9 \\
\hline Stroke medicine & 42 & 21 \\
\hline All specialties & 2,478 & 23 \\
\hline
\end{tabular}




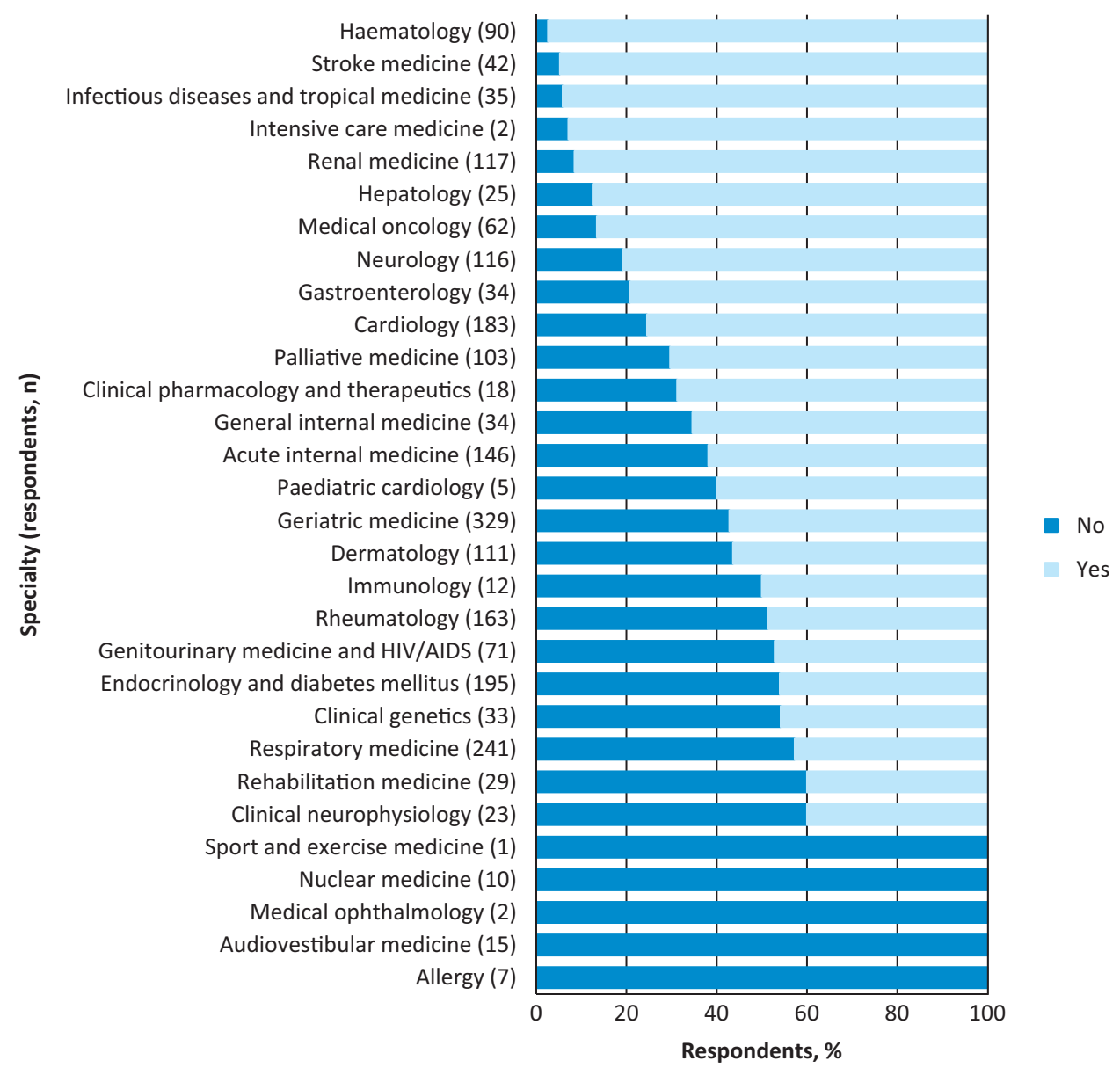

Fig 1. Does your specialty provide a specialty-specific formal on-call rota? Answers expressed as a percentage of respondents from each specialty. specialty rota compared to a lower proportion within specialties such as respiratory medicine (42\%) and rheumatology (49\%). Many physicians working in smaller specialties, for example allergy and audiovestibular medicine, did not provide a specialty-specific on-call rota within their hospital.

\section{Do you practise general internal medicine?}

All respondents were asked the above question regarding whether they perceive that they 'practise general internal medicine'. $64 \%$ answered that they did practise GIM compared to $36 \%$ who felt they did not. Responses varied dependent on the primary specialty of the respondent (see Fig 2) ranging from $0 \%$ of respondents practising internal medicine in a number of specialties, including allergy, clinical genetics, clinical neurophysiology, dermatology, medical ophthalmology, nuclear medicine and sports and exercise medicine, to $100 \%$ in acute internal medicine, and over $80 \%$ in endocrinology, geriatric medicine and respiratory medicine. Of note, responses also varied with age of the respondent, with those of a younger age more likely to respond that they did practise GIM than those from an older age group (see Fig 3).

\section{In what roles do you practise general internal medicine?}

For those consultants who did practise GIM, the survey asked in which roles they practised. Respondents from each specialty varied in the roles in which they practised, for example, the majority of acute physicians felt their most common role in GIM was as a dedicated acute care physician, whereas, for cardiologists the majority felt their most common role was in managing the inpatients who presented with a primary cardiological problem but had other general medical needs (Figs 4 and 5).

\section{Do you feel confident in providing higher specialty trainees with training in the following areas?}

All respondents who stated they practised GIM were asked if they acted as an educational or clinical supervisor for higher specialty trainees who were dual certifying in GIM. Consultants who were involved in the supervision of GIM higher specialty trainees ( $74 \%$ of consultants practising GIM) were asked to state whether they were confident in providing training in different areas. $89 \%$ of respondents felt confident in providing training for both running the acute unselected take or managing unselected medical emergencies. $87 \%$ of respondents felt confident in providing training in the full breadth of common medical presentations while $96 \%$ were confident in providing training on the general medical needs of inpatients. Once again, responses varied for each specialty. For training in running the acute unselected take and dealing with acute unselected emergencies, acute internal medicine physicians 


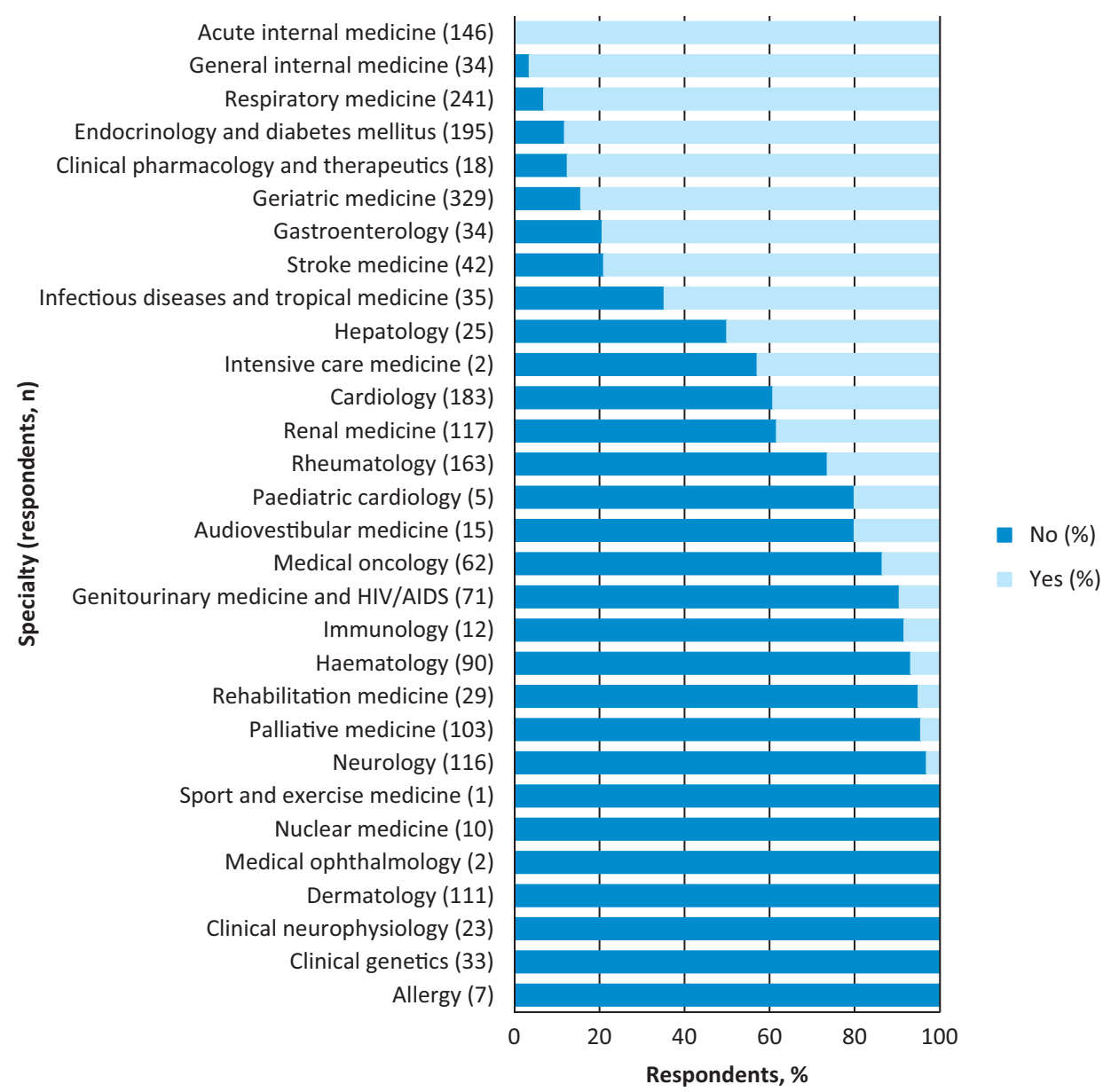

were most confident in providing training (100 and 99\% feeling confident respectively) compared to lower levels of confidence in other specialties who had less of a role in the acute unselected medical take, such as cardiology (65\%) and haematology and hepatology (both 50\%) (Fig 6). In terms of managing the full breadth of general medical problems, over $90 \%$ of physicians

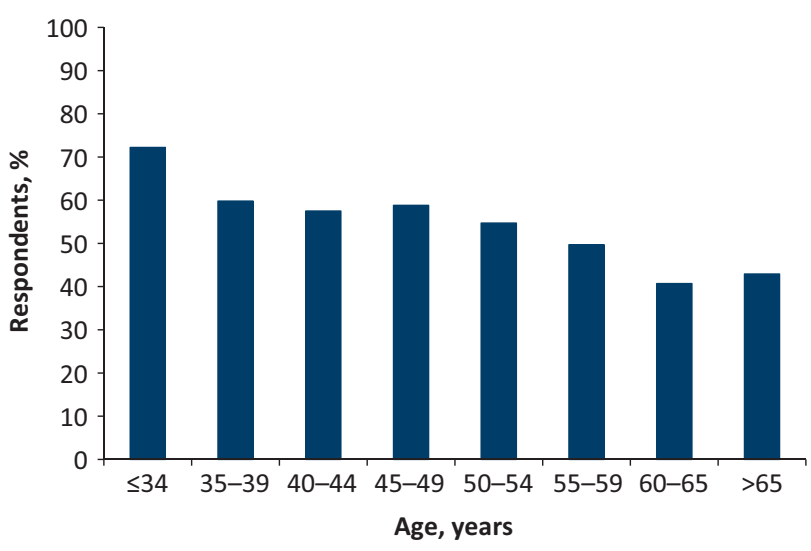

Fig 3. Percentage of respondents from each age group who practise internal medicine. in many specialties felt confident in providing training in this area. Consultant physicians appeared to be most confident in providing training in the management of general medical needs of inpatients ( $>90 \%$ of respondents of all specialties).

\section{Do you feel competent to supervise trainees in the following procedures?}

Respondents who were responsible for the educational or clinical supervision of GIM trainees were asked if they felt competent in supervising trainees for a number of procedures which are included in the GIM curriculum. Results suggested a lack of confidence by consultant physicians in procedural training with overall expressions of feeling competent being between 41 and $61 \%$ dependent on procedure. Consultant physicians perceived level of competence varied depending on their specialty, for example, gastroenterologists feeling most competent at training in abdominal paracentesis and respiratory physicians in intercostal drain insertion (Fig 7).

How much time in training for general internal medicine should be spent on the following areas?

Those involved in the educational and clinical supervision of trainees were asked what percentage of training time should be 


\begin{tabular}{|c|c|c|c|c|c|c|}
\hline & 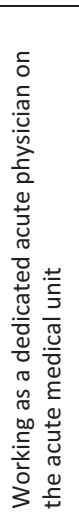 & 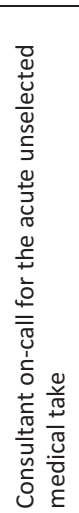 & 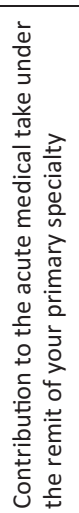 & 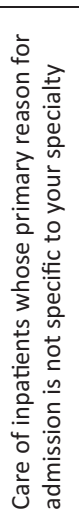 & 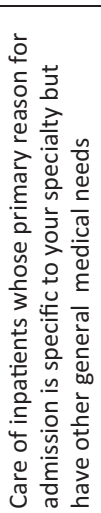 & 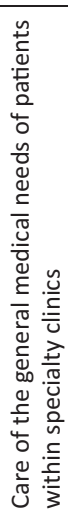 \\
\hline Acute internal medicine & 96 & 66 & 20 & 34 & 24 & 21 \\
\hline $\begin{array}{l}\text { Clinical pharmacology and } \\
\text { therapeutics }\end{array}$ & 36 & 71 & 29 & 71 & 57 & 71 \\
\hline $\begin{array}{l}\text { Endocrinology and diabetes } \\
\text { mellitus }\end{array}$ & 23 & 85 & 27 & 79 & 67 & 50 \\
\hline Gastroenterology & 3 & 61 & 41 & 83 & 76 & 36 \\
\hline General internal medicine & 44 & 78 & 26 & 67 & 30 & 44 \\
\hline Geriatric medicine & 15 & 72 & 32 & 56 & 66 & 55 \\
\hline $\begin{array}{l}\text { Infectious diseases and tropical } \\
\text { medicine }\end{array}$ & 21 & 63 & 33 & 71 & 87 & 54 \\
\hline Respiratory medicine & 9 & 70 & 26 & 71 & 78 & 50 \\
\hline Rheumatology & 31 & 68 & 27 & 68 & 51 & 42 \\
\hline Stroke medicine & 7 & 70 & 50 & 50 & 70 & 43 \\
\hline & 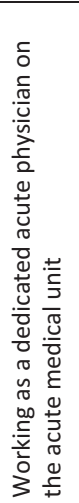 & 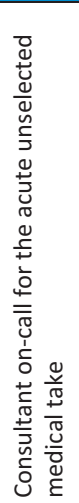 & 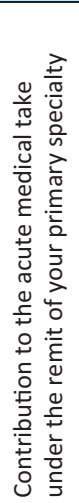 & 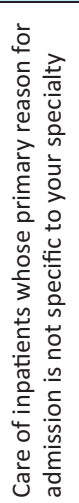 & 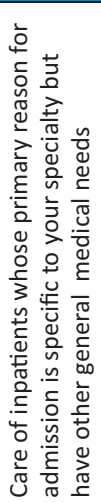 & 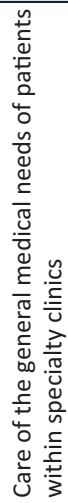 \\
\hline Audiovestibular medicine & 0 & 0 & 50 & 50 & 50 & 100 \\
\hline Cardiology & 8 & 57 & 47 & 61 & 76 & 36 \\
\hline $\begin{array}{l}\text { Genitourinary medicine and } \\
\text { HIV/AIDS }\end{array}$ & 0 & 0 & 14 & 0 & 86 & 57 \\
\hline Haematology & 0 & 0 & 13 & 0 & 50 & 38 \\
\hline Hepatology & 0 & 42 & 33 & 75 & 75 & 42 \\
\hline Immunology & 0 & 0 & 100 & 0 & 100 & 100 \\
\hline Intensive care medicine & 29 & 29 & 29 & 43 & 57 & 29 \\
\hline Medical oncology & 0 & 0 & 25 & 13 & 75 & 50 \\
\hline Neurology & 20 & 0 & 40 & 0 & 60 & 20 \\
\hline Palliative medicine & 0 & 0 & 0 & 0 & 33 & 0 \\
\hline Rehabilitation medicine & 0 & 0 & 0 & 0 & 50 & 50 \\
\hline Renal medicine & 10 & 60 & 48 & 79 & 86 & 74 \\
\hline
\end{tabular}

Fig 4. For specialties with a (a) high contribution to acute unselected medical take ( $>60 \%$ respondents) and (b) lower contribution to acute unselected medical take ( $<60 \%$ respondents): In what roles do you practise general internal medicine? Results expressed as a \% of respondents from each specialty. 


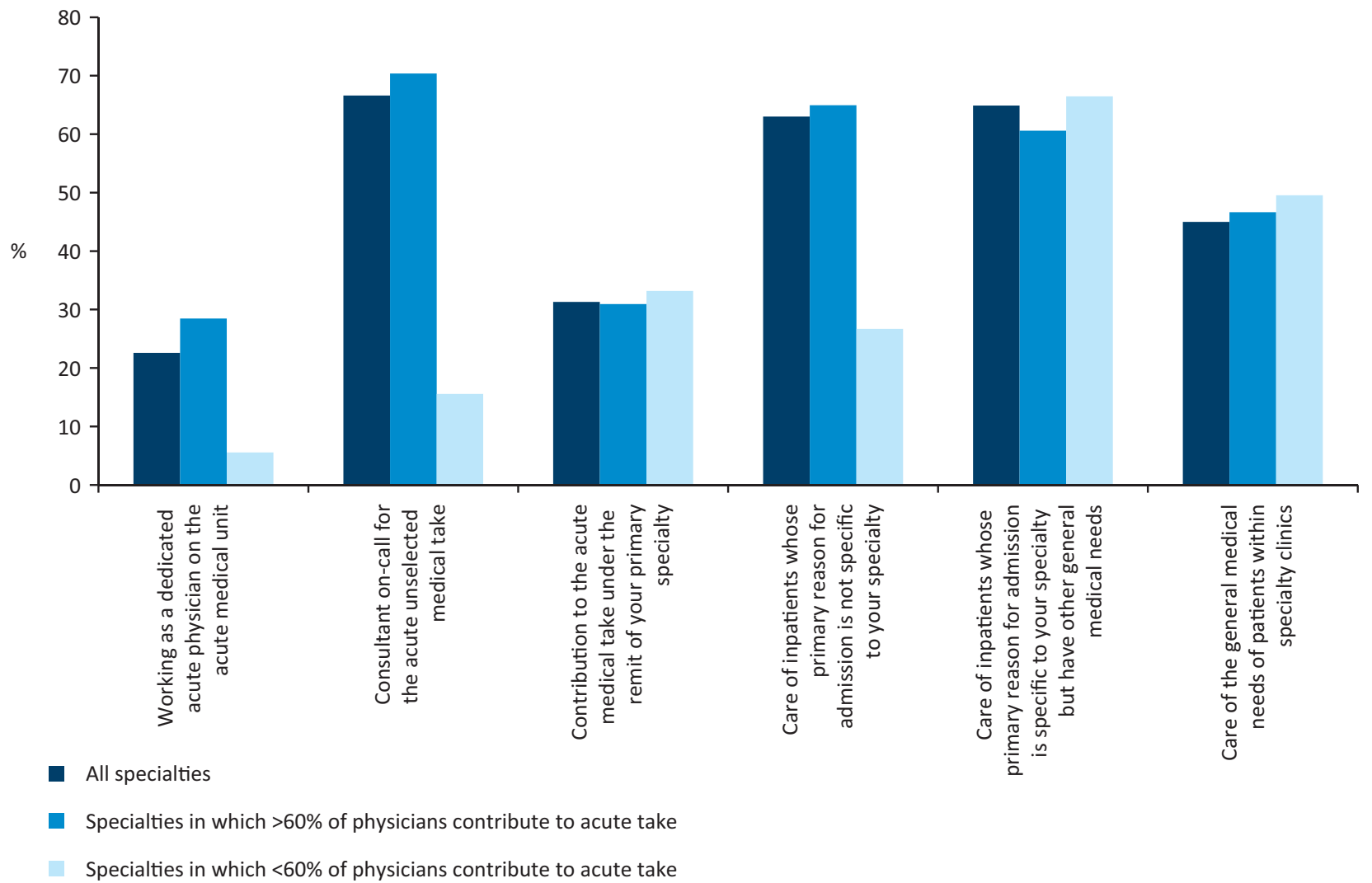

Fig 5. Do you practise general internal medicine in the following roles? Expressed as \% of consultant physicians who practise internal medicine in each role.

Fig 6. Percentage of respondents in each specialty who feel confident providing training in the following areas to higher specialty trainees in general internal medicine.

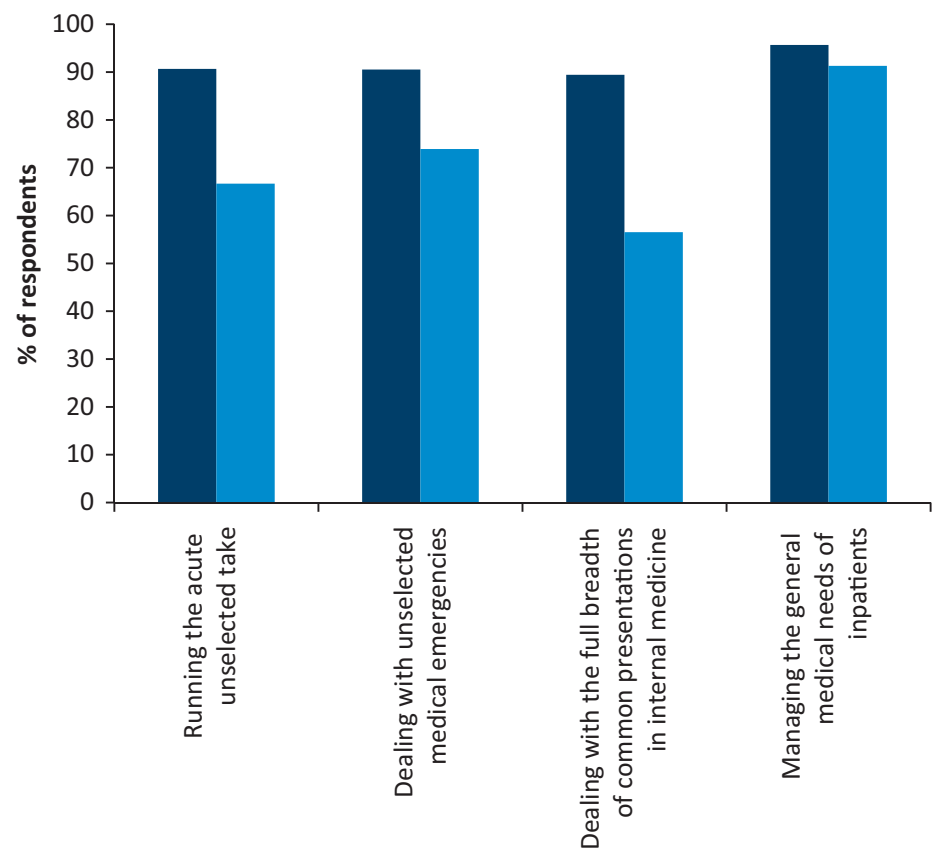

- Specialties with $>60 \%$ of participants practicing GIM as a dedicated acute physician or consultant on-call for the acute take

- Specialties with $<60 \%$ of participants practicing

GIM as a dedicated acute physician or consultant on-call for the acute take 


\begin{tabular}{|c|c|c|c|c|c|c|}
\hline & 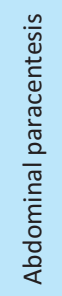 & 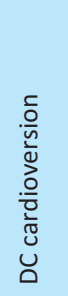 & 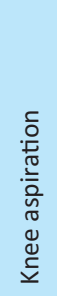 & 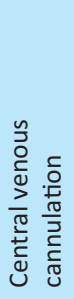 & 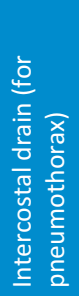 & 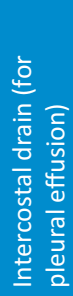 \\
\hline Acute internal medicine & 85 & 83 & 62 & 71 & 79 & 74 \\
\hline Cardiology & 39 & 100 & 26 & 81 & 52 & 48 \\
\hline $\begin{array}{l}\text { Clinical pharmacology and } \\
\text { therapeutics }\end{array}$ & 54 & 62 & 38 & 15 & 38 & 23 \\
\hline $\begin{array}{l}\text { Endocrinology and } \\
\text { diabetes mellitus }\end{array}$ & 51 & 44 & 37 & 33 & 40 & 39 \\
\hline Gastroenterology & 96 & 51 & 22 & 34 & 36 & 35 \\
\hline General internal medicine & 82 & 88 & 63 & 50 & 71 & 71 \\
\hline Geriatric medicine & 52 & 51 & 65 & 28 & 37 & 35 \\
\hline Haematology & 100 & 0 & 0 & 100 & 100 & 100 \\
\hline Hepatology & 100 & 20 & 20 & 60 & 40 & 50 \\
\hline $\begin{array}{l}\text { Infectious diseases and } \\
\text { tropical medicine }\end{array}$ & 57 & 64 & 57 & 36 & 36 & 29 \\
\hline Intensive care medicine & 50 & 100 & 50 & 100 & 100 & 100 \\
\hline Renal medicine & 52 & 52 & 38 & 81 & 43 & 43 \\
\hline Respiratory medicine & 42 & 52 & 34 & 37 & 97 & 94 \\
\hline Rheumatology & 50 & 54 & 100 & 41 & 46 & 50 \\
\hline Stroke medicine & 41 & 53 & 59 & 24 & 35 & 44 \\
\hline All specialties & 61 & 57 & 47 & 42 & 55 & 53 \\
\hline
\end{tabular}

Fig 7. Do you feel competent in supervising trainees in the following procedures? Expressed as a \% of respondents from each specialty who felt competent in performing the procedure. Light blue $=$ essential to be independ ent as a higher specialty trainee; dark blue = desirable to be independent and must have hands-on experience as a higher specialty trainee.

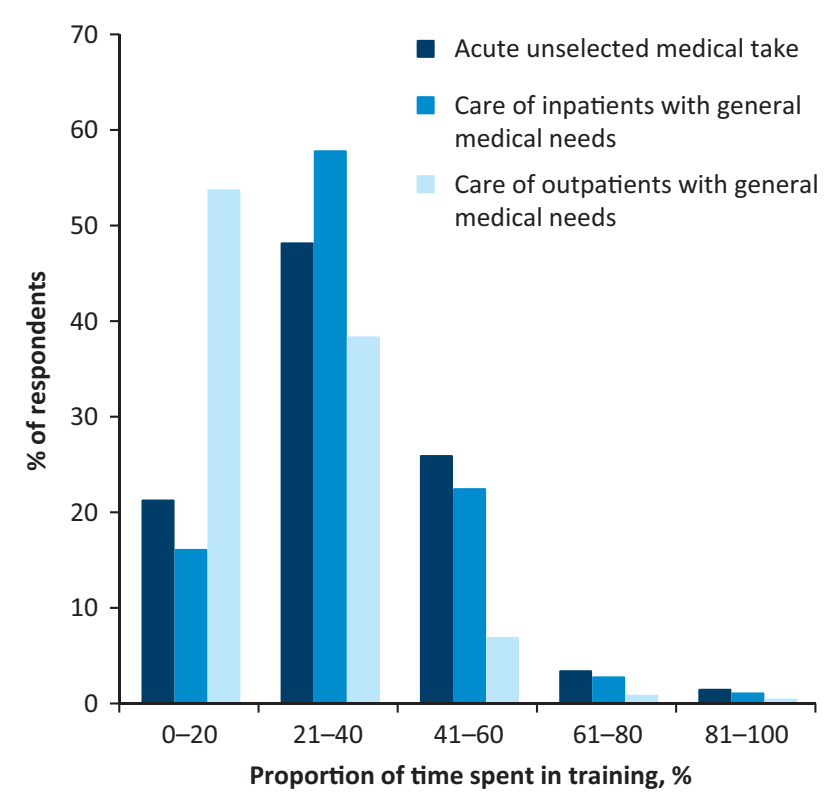

Fig 8. What proportion of training time in general internal medicine should be spent on the following areas? spent on different areas of GIM training (Fig 8). The majority of respondents felt training time should be divided with $20-40 \%$ of time spent on managing the acute unselected take, $20-40 \%$ of time on managing the general medical needs of inpatients and $0-20 \%$ of time on managing the general medical needs of outpatients.

\section{Discussion}

Jane Dacre, president of the RCP, has stated 'generalism makes a better specialist' and that 'as the population gets older we ignore generalism at our peril'? The Future Hospital Commission highlighted the need for increased general medical skills within the physician workforce. ${ }^{8}$ There is an urgent need therefore to clarify what we as physicians understand by general medicine, how it is currently practised and how training should be changed to support the needs of our patients. This survey increases our understanding of all of these.

\section{Response rate}

The survey was completed by $23 \%$ of those who were sent the initial email link. While this may be initially viewed as low it is 
typical of such electronic surveys of doctors. Although there is some variation between specialty response rates, the responses are broadly similar and are representative of the age and gender demographic of the consultant population.

\section{Perception of general internal medicine among consultant physicians}

Perception of the practise of GIM by consultant physicians varied significantly depending on specialty. Those who do not traditionally dual certify in their specialty and GIM were far more likely to declare they do not practise it (eg audiovestibular medicine, allergy medicine, dermatology and medical ophthalmology). Similarly those who worked mainly in the outpatient setting were less likely to declare that they practised roles within GIM than those who were involved in the care of inpatients. Importantly, this suggests a lack of acknowledgement of the general medical care we offer patients in an outpatient setting. Specialties with a larger inpatient workload, but who did not always contribute to the acute take, were more likely to state they practised internal medicine than those with mainly outpatient workloads but, far less likely than those specialties who contributed to the acute unselected medical take. This again, shows that some consultants do not acknowledge the holistic nature of medicine and that patients require doctors with a broad set of physicianly skills and knowledge.

These observations are at odds with the definition of GIM provided by the GMC (which states that GIM encompasses the care of inpatients and outpatients as well as acute medical problems ${ }^{12}$ ) as well as that suggested by the Future Hospital Commission. ${ }^{6}$ Interestingly, when probed more deeply about the roles they take on in GIM, those who declared they did practise in this area rated the role they played in care of the general medical needs of inpatients as highly as that as the consultant on call for the acute unselected take.

As expected, the roles in which consultant physicians practise GIM varied with each specialty; for example acute physicians playing a far greater role in the acute setting than specialties such as renal medicine who more commonly used their general medical skills for inpatients. This suggests that the role of GIM for physicians is not universal but varies depending on the specialty and skills of the consultant physician and the setting in which they are working.

Consultants of a younger age group were more likely to state that they practised GIM. This is somewhat surprising and can be explained in a number of ways. It may reflect the unclear distinction between general and acute medicine, and consultants ceasing to work as part of the acute take in later career stages due to workload and pressures in this environment. However, given the recent drive for increasing general medical skills and the current pressures in the NHS, it may also be driven by NHS employers driving a market in which a consultant physician offering general medical skills is more likely to be appointed than one without.

\section{Training in general internal medicine}

While many specialties felt confident in managing the general medical needs of inpatients, approximately $10 \%$ of all consultant physicians lacked confidence in managing the acute take, unselected medical emergencies and the full breadth of medical conditions. There was also a lack of perceived competence in supervising trainees with procedural skills. Within free text provided by some respondents it was highlighted many times that the balance between keeping up to date with specialist skills and generalist skills in an environment in which developments are occurring rapidly and time is very limited is proving increasingly challenging. Consultants need to be supported to have the time away from direct clinical care of patients to maintain their generalist as well as their specialist skills in order to provide adequate patient care.

Of note, there was large variation in confidence in training in different areas, particularly in supervising trainees in procedural competencies, among different specialties. Unsurprisingly, those specialties which are more procedural based feel happier to supervise trainees in relevant procedures. If we continue to require our trainees to be competent in these skills and procedures we need to ensure exposure to those who are able to teach them competently, regardless of whether that person is within the trainee's primary training specialty.

The survey has given good evidence of how consultants feel we should train in GIM. A 40:40:20 split between the acute take, ward patients and outpatients was clearly preferred. This should be considered separate from specialty training and suggests that current service pressures on medical trainees (and in particular their support of the acute take) have a negative effect on their general medical training. Reversing this will be a big challenge.

\section{Conclusion}

This survey has highlighted that the concepts of 'generalism' and 'general internal medicine' continue to be somewhat unclear, with differing perceptions dependent on physician specialty. What is apparent is that the practice of general medicine extends well beyond that of the acute unselected take into the continued care of both inpatients and outpatients. It is clear that in developing the future of both the practice and training of GIM, we cannot take a 'one-size-fits-all' approach but must develop our general medical skills as a profession based on the needs of the patients we care for.

\section{References}

1 Office of National Statistics. United Kingdom National Life Tables 1980-82 to 2011-13. Newport: ONS, 2015. Available online at http://ons.gov.uk/ons/taxonomy/index.html?nscl=Life+Tables\#tabdata-tables. [Accessed 5 November 2015].

2 Dilnot A, Warner N, Williams J. Fairer Care Funding. Commission on funding of care and support. London: DH, 2011.

3 Health and Social Care Information Centre. Hospital Episode Statistics (admitted patient care) England 2013/14. Leeds: HSCIC, 2015. Available online at www.hscic.gov.uk/searchcatalogue? productid $=17192 \& \mathrm{q}=$ title $\% 3 \mathrm{a} \% 22 \mathrm{Hospital}+$ Episode + Statistics $\% 2 \mathrm{c}$ +Admitted+patient+care+-+England\%22\&sort=Relevance\&size $=$ 10\&page $=1 \#$ top [Accessed 5 November 2015].

4 Royal College of Physicians. Hospitals on the edge? The time for action. London: RCP, 2012.

5 Thomas R. Dacre: Ignore generalist training at your peril. Health Service Journal, 7 July 2015. Available online at http://m.hsj. co.uk/5087162.article [Accessed 5 November 2015].

6 Future Hospital Commission. Future hospital: caring for medical patients. A report from the Future Hospital Commission to the Royal College of Physicians. London: RCP, 2013. 
7 Greenaway D. Shape of training. Securing the future of excellent patient care. London: Shape of Training, 2013.

8 British Medical Association. Little need for more generalism. London: BMA, 2013. Available online at http://bma.org.uk/newsviews-analysis/news/2013/february/little-need-for-more-generalism [Accessed 5 November 2015].

9 Goddard A, Evans T, Phillips C. Medical Registrars in 2010: experience and expectations of future consultant physicians of the UK. Clin Med 2011;11:532-5.

10 Royal College of Physicians. The medical registrar: empowering the unsung heroes of patient care. London: RCP, 2013.

11 Federation of the Royal Colleges of Physicians of the United Kingdom. Census of consultant physicians and medical registrars in the UK, 2013-14: data and commentary. London: RCP, 2014.
12 Joint Royal College of Physicians Training Board. Specialty training curriculum for general internal medicine. London: JRCPTB, 2009 (updated 2012). Available online at www.jrcptb.org.uk/sites/default/ files/2009\%20GIM\%20(amendment\%202012).pdf. [Accessed 5 November 2015].

Address for correspondence: Dr A Goddard, Royal College of Physicians, 11 St Andrews Place, Regent's Park, London, NW1 4LE, UK.

Email: andrew.goddard@rcplondon.ac.uk

\title{
What makes a good clinical app? Introducing the RCP Health Informatics Unit checklist
}

\author{
Authors: Jeremy C Wyatt, ${ }^{\mathrm{A}}$ Harold Thimbleby, ${ }^{\mathrm{B}}$ Paul Rastall, ${ }^{\mathrm{C}}$ Jan Hoogewerf, ${ }^{\mathrm{D}}$ Darren Wooldridge ${ }^{\mathrm{E}}$ and \\ John Williams ${ }^{\mathrm{F}}$
}

Doctors increasingly rely on medical apps running on smart phones or tablet computers to support their work. However, these apps vary hugely in the quality of their data input screens, internal data processing, the methods used to handle sensitive patient data and how they communicate their output to the user. Inspired by Donabedian's approach to assessing quality and the principles of good user interface design, the Royal College of Physicians' Health Informatics Unit has developed and piloted an 18-item checklist to help clinicians assess the structure, functions and impact of medical apps. Use of this checklist should help clinicians to feel more confident about using medical apps themselves, about recommending them to their staff or prescribing them for patients.

KEYWORDS: Medical apps, mHealth, quality assessment checklist, Donabedian's structure, process, outcome, health informatics, clinical use of technology

Authors: ${ }^{\text {A }}$ leadership chair in eHealth research, Leeds Institute of Health Sciences, Leeds, UK, and clinical advisor on new technologies, HIU, RCP, London, UK; ${ }^{B}$ professor of computer science, Swansea University, Swansea, UK, and expert advisor on IT, HIU, RCP, London, UK; C Clinical research fellow, Neath Port Talbot Hospital, Port Talbot, UK, and clinical fellow, HIU, RCP, London, UK; Pprogramme manager, HIU, RCP, London, UK; Eproject manager, HIU, RCP, London, UK; Fprofessor of health services research, Swansea University, Swansea, UK, and director, HIU, RCP, London, UK

\section{Analysis and problem statement}

Smart phone apps are potentially very useful additions to clinical practice and are widely used by junior and senior doctors to support their work. Preliminary results of a 2015 survey of 1,104 Royal College of Physicians (RCP) members and fellows (response rate after two reminders $42 \%$ of the 2,658 members of the RCP research panel) show that 586 (54\%) use apps to support their clinical work and of these, $42 \%$ believed the apps were 'essential' or 'very important' to their work. However, the survey also reveals that $43 \%$ - nearly half - of respondents were concerned about some aspects of app quality. The concern shown by RCP members and fellows about app quality is very appropriate, as several studies have shown that the quality of some apps varies too much for safe clinical use without prior assessment. For example, a study of 23 calculators for converting opioid drug dose equivalents, ${ }^{1}$ found dangerously large variations in calculated doses. Conversion of a $1 \mathrm{mg}$ dose of oral morphine to methadone resulted in a dose ranging from 0.05 to $0.67 \mathrm{mg}$ methadone (a 13:1 range), with fewer than half the apps recognising that the conversion formula used should depend on the actual dose as well as on the drugs concerned. Thimbleby et $a l^{2}$ found that the delete key on many apps does not work correctly, so ironically if a user tries to correct an error they notice, that correction may cause an error they do not notice.

\section{Proposed solution}

Building on Donabedian's classical 1978 analysis of the factors that determine the quality of medical care ${ }^{3}$ and with input 